\title{
Processos relacionais em cartas publicitárias $^{*}$ (Relational processes in direct sales letters)
}

\author{
Rodrigo Esteves de Lima-Lopes
}

Faculdade Cásper Líbero / UNIFIEO ${ }^{1}$

\begin{abstract}
RESUMO: Este artigo analisa a instanciação de processos relacionais em um corpus de 104 cartas de mala direta, de forma a observar como os participantes da interação (empresa remetente, produto e destinatário) são caracterizados. A metodologia utilizada contou com um sistema de etiquetagem, com ferramentas computacionais de análise (MANSON, 1999; SCOTT, 1999) e com a comparação entre o corpus de pesquisa e uma fração do Banco de dados de Português, mantido pelo LAEL PUC-SP. Resultados mostram um conjunto de funçōes específico para cada participante.
\end{abstract}

PALAVRAS-CHAVE: Gramática Sistêmico-Funcional; Transitividade; Ressonância.

ABSTRACT: This paper aims at analysing the instantiation of relational processes in a corpus of 104 direct sales letters, in order to study which are the roles ascribed to each interactant (the company, the addressee and the product). Corpus Linguistics was the main methodological tool: two softwares for lexical analysis (MANSON, 1999; SCOTT, 1999) were used and a tagging system was developed. The outcomes were compared with part of the Bank of Brazilian Portuguese, maintained by LAEL - PUC-SP. Results show a set of functions that seems to be specific to each interactant.

KEY-WORDS: Systemic-Functional Grammar; Transitivity; Resonance.

\section{Introdução}

Neste artigo, estudo a realização dos processos (ou verbos) relacionais (HALLIDAY, 1994; HALLIDAY; MATTHIESSEN, 1999, 2004) em 104 cartas de venda de produtos / serviços, comumente chamadas de cartas de mala

\footnotetext{
* Este artigo é uma adaptação e ampliação do capítulo de análise de dados da dissertação de mestrado por mim apresentada (LIMA-LOPES, 2001) no Programa de Pós-graduação em Lingüística Aplicada e Estudos da Linguagem (LAEL) da PUC-SP, sob orientação da Profa. Dra. Leila Barbara.

${ }^{1}$ E-mail do autor: rll307@uol.com.br
} 
direta, ou cartas comerciais. $\mathrm{O}$ foco de análise são as entidades que realizam os papéis de transitividade dentro desses processos. Minha hipótese é que, ao realizar papéis específicos dentro do sistema de transitividade (sistema esse explicado mais adiante), esses participantes são caracterizados de acordo com uma determinada representação de mundo que, por conseguinte, lhes atribui um determinado valor dentro do universo ali construído.

Neste estudo, utilizo a Gramática Sistêmico-Funcional (doravante GSF), idealizada por M. A. K. Halliday (HALLIDAY, 1973, 1978, 1985, 1994; HALLIDAY; MATTHIESSEN, 1999, 2004) como arcabouço teórico. Nessa abordagem, a gramática é um princípio que organiza as funções realizadas pelos falantes, sendo que essas funções têm caráter não-aleatório e são influenciadas pelas relações sociais (EGGINS, 1994, p. 4). A gramática ganha um cunho probabilístico (HALLIDAY, 1992a, b, 1993), uma vez que, ao realizar uma proposição, o falante está escolhendo entre diferentes formas de realização. Isso faz com que cada escolha realizada influencie e seja influenciada pelas demais à sua volta (THOMPSON, 1996, p. 30).

As cartas comerciais são documentos bem flexíveis, servindo a uma série de propósitos (PINHO, 1990, p. 65). Elas podem, em alguns contextos, ser equivalentes a uma conversa face-a-face, mas com uma diferença: a carta é um instrumento de comunicação irreversível (CESCA, 1995, p. 68-69). Isso gera uma grande possibilidade de mal-entendimento, uma vez que, dependendo do contexto e do assunto tratado no documento, a carta pode não ser bem recebida pelo destinatário. Para Cesca (1995), é importante encarar esse tipo de documento não apenas como um veículo de transmissão de informações - sem qualquer outra implicação -, uma vez que, dentre algumas de suas possíveis funções, está a criação de novos negócios.

As cartas de venda de produtos ou serviços são documentos em que uma empresa anuncia um produto/serviço fabricado/prestado por ela (PINHO, 1990), promovendo sua venda a um consumidor potencial, que é o destinatário das cartas. A autoria desses documentos é atribuída à empresa remetente, embora a maioria dos documentos seja assinada por um representante da empresa. Além do estabelecimento de novos negócios (NUS, 1999), as cartas de venda podem ser usadas para re-estabelecimento de relaçōes interrompidas.

Existem vários participantes nas cartas, sendo que em três está o foco deste estudo: a Empresa Remetente (que vende produtos/serviços), o produto/ serviço (o que é vendido) e o Destinatário (para quem o documento é endereçado). Segundo Pinho (1990, p. 67-70), as cartas de venda são escritas e enviadas a consumidores potenciais, ou seja, pessoas que podem estar interessadas na aquisição de determinado produto/serviço. Esses documentos 
são, normalmente, produzidos em série; isso traz dificuldade na impressão de um caráter pessoal (CESCA, 1995), o que seria um dos requisitos para o sucesso de seu propósito (PINHO, 1990, p. 70).

Este estudo contribui para a compreensão desse gênero à medida em que levanta quais são os padrões de escolha dos processos, determinando qual o papel atribuído a cada uma das entidades representadas. Ao mesmo tempo, ele ajuda a aumentar o espectro de estudos sobre transitividade em nosso idioma; como discutirei mais adiante, o português ainda é bastante carente em estudos nessa área.

De forma a realizar seu objetivo, este artigo será dividido em 4 partes. $\mathrm{Na}$ primeira, discutirei os referenciais teóricos utilizados neste trabalho, levantando questóes sobre o sistema de transitividade, com ênfase nos processos relacionais. A seguir, exporei os processos metodológicos e a análise de dados, finalizando com algumas considerações sobre as contribuições deste estudo.

\section{Fundamentação teórica}

Este trabalho tem como base teórica a Gramática Sistêmico-Funcional, desenvolvida por Halliday (HALLIDAY, 1973, 1978, 1985, 1994; HALLIDAY; HASAN, 1976; HALLIDAY; MATTHIESSEN, 1999, 2004) e seguidores (EGGINS, 1994; MARTIN; MATTHIESSEN; PAINTER, 1997; THOMPSON, 1996, 2004). Desde os anos 60, a GSF vem se desenvolvendo como um modelo de análise lingüística que se caracteriza por uma abordagem paradigmática que tem seu foco na linguagem enquanto fruto do seu contexto social.

Ao realizar um significado através de um item lexical ou fraseado (wording), o falante está realizando uma escolha dentre outras prováveis, fazendo com que o uso da língua tenha um caráter probabilístico (HALLIDAY, 1991, 1992, 1993). Os significados são instanciados na realização lingüística; assim, o conceito de instanciação pode ser definido como o contínuo entre um significado potencial e suas diferentes formas de expressão lingüística. Os níveis mais abstratos desses significados seriam representados pelo gênero, ou contexto de cultura, ao passo que a realização lingüística é mediada pelo registro, ou contexto de situaçãa. É importante ressaltar que essas escolhas podem não estar em um nível consciente (THOMPSON, 1996, p. 8).

Diferentemente de todas as abordagens desenvolvidas até então, Halliday propõe um modelo de análise tridimensional, ou seja, ao realizarmos açôes por meio da linguagem estamos, de fato, realizando três tipos de significados simultâneos: 
1) significados relativos às representaçôes de poder e solidariedade, o que engloba as atitudes em relação ao outro e os papéis sociais assumidos;

2) significados relativos à organização do conteúdo da mensagem, relacionando o que se diz ao que foi dito;

3) significados relativos à representação da experiência através da língua, sobre o que se fala e sobre quem (ou o que) age sobre quem (ou o que).

Cada um desses tipos de significado está relacionado a uma Metafunção da Linguagem, sendo que cada Metafunção possui um sistema que viabiliza a realização de seus significados. Assim, o item 1 está relacionado à Metafunção Interpessoal (realizada pelo sistema de Modo); o item 2 à Metafunção Textual (realizada pelo sistema Temático) e o item 3 à Metafunção Ideacional (realizada pelo sistema de Transitividade). Essa última é o foco deste trabalho.

A Metafunção Ideacional é a responsável pela expressão da nossa representação do mundo, estando ligada tanto ao mundo externo (eventos, acontecimentos etc.) como ao nosso mundo interno (pensamentos, crenças, sentimentos etc.) (HALLIDAY, 1973, 1978, 1985, 1994; HALLIDAY; MATTHIESSEN, 1999, 2004). A instanciação dessa Metafunção ocorre por meio do Sistema de Transitividade, que envolve o falante em um sistema que pressupóe a escolha de processos (ou verbos) e seus argumentos (participantes e elementos circunstanciais) (EGGINS, 1994, p. 220). Halliday (HALLIDAY, 1973, 1978, 1985, 1994; HALLIDAY; MATTHIESSEN, 1999, 2004) e Thompson $(2004,1996$, p. 78) chamam a atenção para o fato de o termo transitividade não ser utilizado com o mesmo significado da gramática tradicional. Na última, o termo está ligado à classificação dos verbos a partir da presença ou ausência de complementos e preposiçóes, ao passo que na GSF, a transitividade é um sistema que permite que o falante traduza ou retrate seu mundo, bem como as entidades nele presentes, em escolhas lingüísticas. Um exemplo seria (ex. 1), a seguir, no qual optamos por representar a menina como realizadora da ação de falar, seu pai como participante receptor dessa ação, ao passo que ontem é uma circunstância de tempo. Vale ressaltar que, ao observarmos essas escolhas em textos orais ou escritos, podemos compreender como o escritor/falante atribui significado ao mundo a sua volta.

Ex. 1

\begin{tabular}{|c|c|c|c|}
\hline A menina & falou com & seu pai & ontem \\
\hline Participante & Processo & Participante & Circunstância \\
\hline
\end{tabular}


Para Halliday (1994, 1985), nossa experiência deve ser traduzível por meio de um número tangível de processos. Segundo Halliday e Mathiessen (2004), esses processos são: Materiais (ações no mundo físico), Mentais (experiências em nosso mundo interior), Relacionais (significados ligados à identificação, à classificação e à posse), Comportamentais (representando ações com caráter físico e mental), Verbais (processos de dizer) e Existenciais (processos de existir, que refletem o reconhecimento da existência de uma entidade).

Cada um desses processos possui um número determinado de participantes, definidos de acordo com as características semânticas de cada um deles. Como já colocado, meu foco neste trabalho será a análise dos processos relacionais e, por isso, deles trataremos a seguir.

Halliday e Matthiessen (2004, p. 215) afirmam que todas as línguas possuem formas de expressar significados relacionais, os quais podem ser divididos em: 1) Intensivos; 2) Circunstanciais e 3) Possessivos. Os intensivos estão relacionados à caracterização, expressando significados do tipo X é/estáY. Os circunstanciais relacionam uma entidade a uma circunstância, expressando significados do tipo X está em/como X. Finalmente, os possessivos estabelecem uma relação de posse/pertença, expressando significados do tipo X tem Y. Essas três relações (HALLIDAY, 1985, 1994 e HALLIDAY; MATTHIESSEN, 2004) podem exercer duas funções dentro do sistema de transitividade: Atribuir e Identificar. O primeiro tipo expressa significados em que uma classe/ característica é atribuída a uma determinada entidade do discurso; ao passo que no segundo tipo, uma entidade tem uma identidade atribuída a ela. Ao relacionarmos esses dois significados aos três já mencionados, temos 6 diferentes significados:

1. Intensivo Atributivo: Sara [Participante: Portador] é [Processo: relacional atributivo] sábia [Participante: atributo].

2. Intensivo Identificativo: Sara [Participante: Identificado] é [Processo: relacional identificativo] a líder [Participante: Identificador].

3. Possessivo Atributivo: Pedro [Participante: Possuidor] tem [Processo: relacional atributivo] um piano [Participante: Possuído].

4. Possessivo Identificativo: O piano [Participante: Possuidor] é [Processo: relacional Identificativo] do Pedro [Participante: Possuído].

5. Circunstancial Atributivo: A defesa [Participante: Portador] é [Processo: relacional atributivo] numa quinta [Participante: Atributo].

6. Circunstancial Identificativo: Amanhã [Participante: identificado] é [Processo: relacional Identificativo] dia 10 [Participante: Identificador]. 
No item 1, há um processo relacional intensivo atributivo. Nele, os participantes se resumem a dois: o Portador, definido como a entidade inclusa em uma determinada classe ou categoria, e a Característica, que representa essa classe (normalmente acompanhada por um grupo nominal precedido de um artigo indefinido - um, uma, uns, umas). Já no item 2, temos um processo intensivo identificativo. Os participantes desse tipo de processo são o Identificado, que é o alvo da definição, e o Identificador, que é o elemento definidor (o último normalmente acompanhado por um grupo nominal precedido de um artigo definido - $o, a, o s$, as).

No item 3, há um processo relacional possessivo atributivo, com dois participantes: o Possuidor, entidade detentora de posse, e o Possuído, objeto da posse pelo possuidor. Os processos possessivos identificativos (item 4) possuem os mesmos participantes que os intensivos. Por fim, nos itens 5 e 6 , temos os processos Circunstanciais Atributivos e Identificativos, respectivamente. No caso desses processos, um participante é substituído por um Elemento Circunstancial.

Ao analisar os processos Relacionais, tento observar como os participantes de um dado discurso são classificados e caracterizados, trazendo insights importantes sobre as estratégias discursivas utilizadas nesse gênero.

Diversos trabalhos (RAMOS, 1997; LIMA-LOPES, 2001; 2005b; MATTHIESSEN, 1999) demonstram que o sistema de escolhas dentro do sistema de transitividade não é aleatório. Um exemplo seria Lima-Lopes (2005b), que estuda os processos materiais no mesmo corpus utilizado nesta pesquisa. $\mathrm{O}$ autor observou que os processos materiais podem variar de acordo com dois princípios: 1) de acordo com a função que realizam dentro das cartas e 2) de acordo com o campo do discurso. No caso de 1, teríamos processos que realizam funções similares, independentemente da carta em que ocorram. Entre essas funções estariam a apresentação do produto / serviço e a determinação de procedimentos para compra. Em 2, observa-se que as escolhas realizadas em 1 seriam condicionadas pelo tipo de produto / serviço anunciado nas cartas (LIMA-LOPES, 2005b, p. 160). Em outras palavras, diferentes tipos de produtos levam à escolha de diferentes processos, os quais instanciam características ligadas ao campo semântico de cada produto. Dessa forma, um destinatário, por exemplo, ao adquirir uma publicação periódica, assina uma revista, ao passo que, se essa aquisição fosse de um carro, ele o compraria.

Ramos (1997), que estuda diversos documentos da área de negócios em língua inglesa, mostra que existem taxonomias na instanciação dos participantes em todos os processos. A autora mostra que a empresa responsável pelos 
documentos aparece como Ator em processos materiais que indicam a produção desse produto (RAMOS, 1997, p. 194-196). Nesse mesmo estudo, a empresa remetente também instancia participantes em processos relacionais (RAMOS, 1997, p. 198-202). Quando Portador, ela estaria relacionada a palavras de conotação positiva, representando "características que seriam exploradas de acordo com o público-alvo dos textos" (RAMOS, 1997, p. 199), função que também se repete na instanciação dos Identificados. Em grande parte dos casos, os Identificadores e as Características, no estudo de Ramos (1997), foram instanciados pelo produto / serviço ou por nominalizações.

Já o trabalho de Matthiessen (1999) explora a freqüência de tipos de processos e sua associação com elementos circunstanciais em uma grande variedade de gêneros. Seus resultados mostram que esses dois elementos não se dão de forma aleatória na língua, servindo aos objetivos comunicacionais desses textos.

Outro ponto a ser observado é que há poucos estudos sobre o sistema de transitividade em língua portuguesa. Entre eles destacam-se os de Bressane (2000), Heberle (1999), Armbrust (2006) e Rodrigues Júnior (2006), que trabalham com reuniōes de negócios, editoriais de revistas femininas, editoriais de jornais e contos em inglês e sua respectiva tradução para o português, respectivamente. Heberle (1999) estuda as escolhas do sistema de transitividade e seu caráter ideológico; a autora analisa as representaçōes das experiências femininas em editoriais de revistas para mulheres no Brasil, buscando demonstrar como a mulher é ideologicamente retratada nesses textos. Entre os resultados da autora, está o fato dessas revistas representarem a mulher como dona de casa, que cuida dos filhos e ocupa seu tempo com futilidades. No caso de Bressane (2000), são levantados os processos presentes em cada estágio da reunião. A autora observa que a instanciação dos processos remete à personificação de entidades não animadas, como a própria imobiliária e seus produtos de locação e venda, além "de uma Coisificação dos clientes e compradores, uma vez que eles são constantemente tratados como Metas em processos materiais" (BRESSANE, 2000, p. 22 e 99). No caso de Heberle (1999), a Transitividade é uma forma de sistematizar as relações ideológicas; em Bressane (2000), o foco principal está nas relações de poder. Este estudo, por sua vez, focaliza a classificação e o levantamento dos padróes de realização dos participantes, por acreditar que a análise do sistema de transitividade é importante na observação de como o escritor produz o seu texto. Armbrust (2006) concentra sua análise na observação da transitividade em construções 
de voz passiva, realizando um estudo comparativo entre o português e o inglês. A autora traz importantes resultados para a compreensão de como essas construçôes são instanciadas nas duas línguas. Já Rodrigues Júnior (2006) demonstra que as personagens de seus contos realizam funções de agente em um número significativo de processos, principalmente os materiais e os comportamentais. O autor ressalta que partes do corpo dessas personagens comumente realizam esses papéis, o que vai além da simples personificação dessas partes.

\section{Metodologia}

Esta pesquisa utiliza a Lingüística do Corpus (doravante LC) como abordagem metodológica. Essa escolha se deve, principalmente, pelas ferramentas de análise que ela disponibiliza, possibilitando o trabalho com grandes quantidades de texto de forma rápida e eficiente. Em linhas gerais, a LC trabalha com a coleta e análise de conjuntos de dados lingüísticos chamados corpora (no singular, corpus) (BERBER SARDINHA, 2000, p. 325), servindo a uma grande diversidade de universos teóricos, como a semântica, a sintaxe e a análise do discurso (MCENERY; WILSON, 1996, p. 2).

Entre suas principais características estão:

1. caráter empírico: na LC, busca-se a explicação do fenômeno lingüistico a partir de generalizações baseadas em exemplos reais de comunicação (McENERY; WILSON, 1996), dando ao estudo da linguagem um caráter empírico (KENNEDY, 1998; BIBER, CONRAD et al., 1999).

2. uso de corpus: como dito há pouco, a LC trabalha com a exploração de corpora, que são dados lingüísticos coletados em situações reais de comunicação e armazenados em formato legível por máquina - machine readable -, possibilitando sua exploração com o uso de ferramentas computacionais. A diferença entre um corpus e um banco de textos está nos critérios de seleção e compilação (KENNEDY, 1998, p. 4), uma vez que um corpus é sistematicamente planejado de forma a realizar uma função específica.

3. uso dos computadores: nessa abordagem, a máquina tem um papel muito importante na análise e levantamento de dados. De acordo com Kennedy (1998, p. 5), apesar da análise de grandes quantidades de texto ser realizável manualmente, elas podem não ser exaustivas ou replicáveis. Para o autor, a chegada do computador, na segunda metade do século XX, trouxe 
grandes modificações para a análise textual. Entre as principais contribuições trazidas por essa ferramenta estão:

- estudo de maiores quantidades de texto;

- possibilidade de levantamento exaustivo;

- maior velocidade de análise;

- maior possibilidade de replicabilidade; e

- maior confiabilidade estatística (adaptado de KENNEDY, 1998. p. 5)

4. caráter quantitativo e qualitativo: Biber et al. (1999, p. 1) afirmam que a LC depende tanto de uma abordagem qualitativa, como quantitativa, uma vez que o simples levantamento numérico de itens lexicais ou expressões nada significa sem a interpretação do pesquisador.

\section{$O$ corpus utilizado}

O corpus desta pesquisa é composto por 104 cartas que vendem uma grande variedade de produtos e serviços, como podemos ver na tabela a seguir:

TABELA 1

Produtos/serviços anunciados nas cartas

\begin{tabular}{|c|c|c|c|c|c|}
\hline & Tipos de cartas & $n^{\circ}$ & & Tipos de cartas & $\mathbf{n}^{\mathbf{o}}$ \\
\hline & Assinaturas de revistas & 7 & & Seguro de Vida & 4 \\
\hline & Anúncios em jornais & 8 & & Seguro saúde & 1 \\
\hline & Guias de férias & 6 & & Seguro educação & 1 \\
\hline Publicações & $\begin{array}{l}\text { Anúncios em revistas } \\
\text { especializadas }\end{array}$ & 9 & Financeiros & Seguro residencial & 2 \\
\hline & Anúncios em revistas & 9 & & Cartão de crédito & 9 \\
\hline & Livros & 2 & & Cartão Fidelidade & 2 \\
\hline Programas $\mathrm{d}$ & eTV & 2 & & Empréstimo & 3 \\
\hline Móveis & & 3 & & Serviços bancários & 3 \\
\hline Vestuário & & 3 & & Concessionária de veículos & 1 \\
\hline Hardware & & 4 & & Congresso & 2 \\
\hline Software & & 4 & & Cursos & 4 \\
\hline Maquinário & & 2 & & Telecomunicações & 4 \\
\hline Coleções & & 4 & & Linhas aéreas & 1 \\
\hline Loja de anim & & 1 & & & \\
\hline Total & & 67 & Total & & 37 \\
\hline
\end{tabular}


A escolha do tipo de produto ou serviço anunciado fugiu parcialmente ao controle, uma vez que metade dos documentos (52 cartas) foi disponibilizada por informantes anônimos, que selecionavam quais documentos seriam cedidos. Outra parte dos documentos ${ }^{2}$ ( 40 cartas) foi obtida do banco de dados do projeto DIRECT ${ }^{3}$ e de minha correspondência pessoal (12 cartas).

As cartas que vendem publicaçôes ou serviços financeiros dividem-se em vários subtipos. No caso das publicações, tem-se a assinatura de jornais e revistas, livros e espaço publicitário para anúncio. Já no grupo financeiro, há cartas que vendem seguros (saúde, escolar, residencial e de vida), cartôes de crédito (internacionais e de afinidade), empréstimos pessoais e serviços bancários diversos (como abertura de contas e carteiras de investimentos).

Todas as cartas foram informatizadas em formato texto simples ( ${ }^{*}$.txt) e nomeadas de acordo com os seguintes critérios: cada uma recebeu a abreviatura $\mathrm{CV}$, seguida de um número aleatório e seqüencial, que determina sua catalogação no corpus; esses números vão de 1 a 104.

Vale ressaltar que a análise e categorização de alguns processos necessitou da utilização de um corpus de referência. A função desse corpus foi dar parâmetros de comparação para análise. Queria-se verificar se as impressões observadas no corpus de estudo também se confirmavam no corpus de referência, com tamanho muito maior e abarcando uma maior quantidade de registros. Esse corpus foi composto por uma porção de textos retirados do Banco de Dados de Português, ${ }^{4}$ totalizando 1,1 milhões de palavras.

\subsection{Procedimentos}

Este estudo contou com o uso dois programas de análise lexical (SINCLAIR, MANSON et al, 1998; MANSON, 1999; SCOTT, 1999) e

\footnotetext{
${ }^{2} \mathrm{O}$ Banco de dados do projeto DIRECT é um corpus de linguagem dos negócios com mais de 2 milhôes de palavras, composto por sub-corpora formados por vários tipos de texto.

${ }^{3}$ DIRECT (Em direção à linguagem dos negócios) é um projeto iniciado em 1989, com sede no LAEL - PUC-SP e que engloba várias universidades no Brasil e no exterior com a finalidade de estudar o uso da linguagem no contexto dos negócios. Mais informaçōes em http://lael.pucsp.br.

${ }^{4} \mathrm{O}$ Banco de Dados de Português é um corpus de português brasileiro com 223 milhões de palavras. Foi criado e é mantido pelo projeto DIRECT no LAEL-PUC-SP. Mais informaçōes podem ser obtidas em: http://lael.pucsp.br/corpora.
} 
um sistema de etiquetagem já utilizado em outros estudos (LIMA-LOPES, 2001, 2005b) e descrito e avaliado em Lima-Lopes (2005a).

Com relação aos programas utilizados, o WordSmith Tools (SCOTT, 1999), e o Qwick (SINCLAIR; MANSON et al, 1998; MANSON, 1999) são programas que englobam várias ferramentas. Nesta pesquisa, utilizei a ferramenta de concordância, que permite a observação de uma ou mais palavras dentro do seu contexto de ocorrência, sendo que o horizonte de estudo (amplitude de palavras à direita e à esquerda levantadas pelo programa) é definido pelo pesquisador, utilizando o próprio corpus informatizado. É possível verificar os colocados (palavras adjacentes à pesquisada), bem como gráficos de dispersão, que mostram em quais partes do texto há a ocorrência de uma dada palavra. Essa ferramenta também proporciona a caracterização dos dados por meio do agrupamento de linhas de concordância em conjuntos. Um exemplo de como esses programas operam pode ser observado na FIG. 1, a seguir, que traz uma janela com linhas de concordância do programa WordSmith Tools, no qual cada linha representa uma linha de concordância, sendo que a palavra pesquisada, ou palavra nódulo, encontra-se no centro.

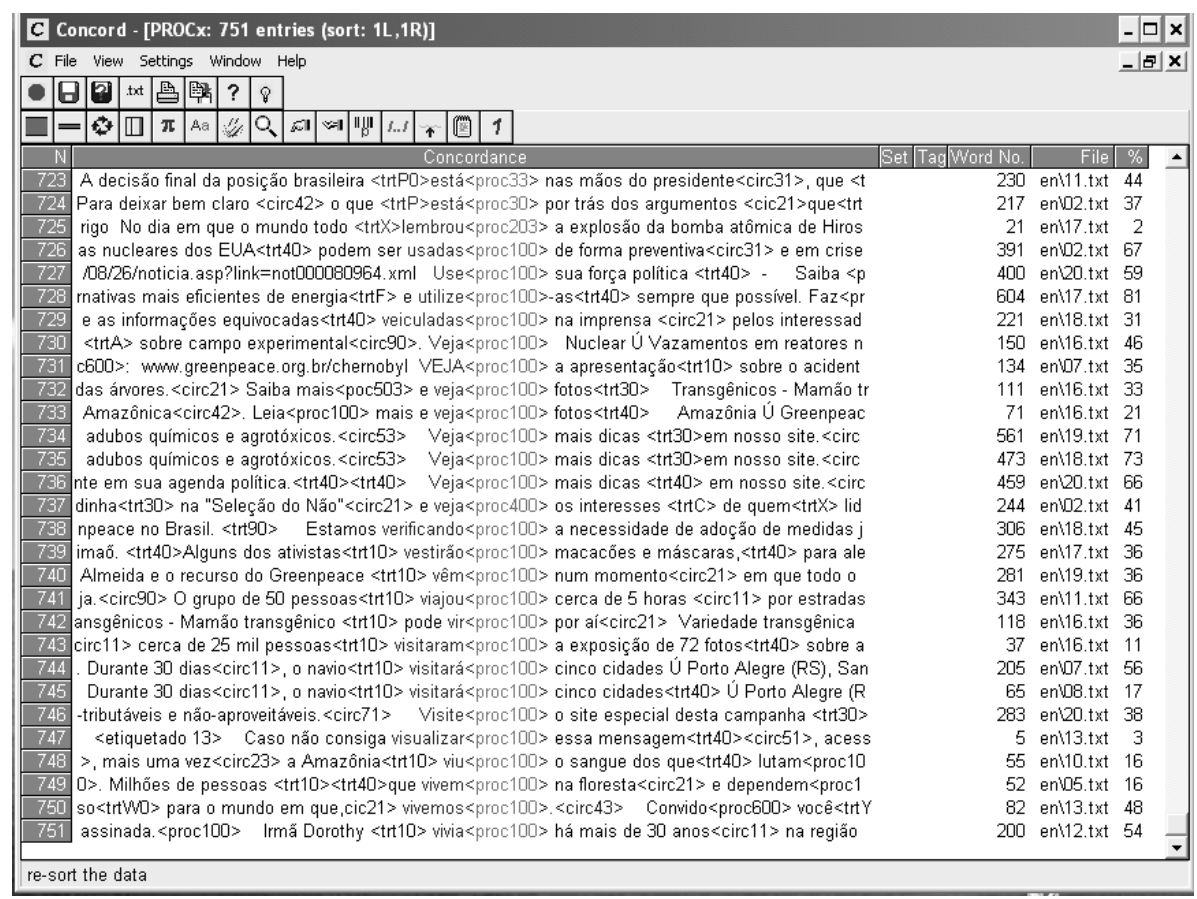

FIGURA 1 - Tela do WordSmith Tools 
Segundo Leech (1991, p. 12), os programas de concordância têm como função o levantamento de elementos discretos, como palavras, expressōes ou pontuações, não conseguindo diferenciar, por exemplo, entre manga (fruta) e manga (camisa). As limitações apontadas por Leech (1991) são pertinentes a esta pesquisa, uma vez que a classificação dos processos depende do contexto e da experiência do pesquisador. Leech $(1991$, p. 12) sugere que esse problema pode ser solucionado através da utilização de corpora anotados (ou etiquetados), o que proporciona uma maior interação entre a máquina, o pesquisador e o corpus. Assim, ao se etiquetar um corpus, a informação que antes era implícita passa a ser explícita e, portanto, recuperável pela máquina (McENERY; WILSON, 1996, p. 24). A solução apontada por Leech foi adotada nesta pesquisa, na qual foi desenvolvido um sistema de anotação como ferramenta de auxílio. A função da etiquetagem neste estudo foi viabilizar o levantamento das estruturas do sistema de transitividade. A utilização desse sistema foi muito importante, pois permitiu a recuperação sistemática e simultânea de todos os dados referentes a um tipo de processo e participante.

O sistema de etiquetagem foi baseado nas categorias do sistema de transitividade. Para cada categoria do sistema, foi criado um código, composto por letras e números, que diferencia cada categoria das demais. O sistema engloba todos os elementos presentes no Sistema de Transitividade e seu funcionamento pode ser observado a seguir:

Ex. 2

Planeta em Fúria $<$ trt71 > é < proc320> a nova coleção de vídeos do ACME Channel $<$ trt82>

Assim que cada folha $<$ trt $40>$ estiver $<$ proc $310>$ completamente preenchida, $<\operatorname{trt} 72>$

O exemplo acima ilustra a utilização desse sistema no corpus desta pesquisa. O grupo nominal "Planeta em Fúria" funciona como Identificado (trt71), ao passo que "nova coleção de vídeos do ACME Channel" (trt82) funciona como Identificador, ambos relacionados por "é" (proc320), que funciona como processo relacional identificativo. No mesmo exemplo, a folha realiza o papel de portador, ao passo que estiver é um processo é um processo relacional atributivo que relaciona $a$ folha a seu atributo preenchido.

Os programas de concordância foram utilizados para levantar as etiquetas referentes a cada elemento do sistema de transitividade: em vez de pesquisar por palavras ou expressões, utilizei os programas para recuperar cada 
tipo de processo estudado e seus participantes. Um exemplo de como esse levantamento foi realizado está presente na FIG. 2, na qual a palavra central pesquisada é representada por uma etiqueta.

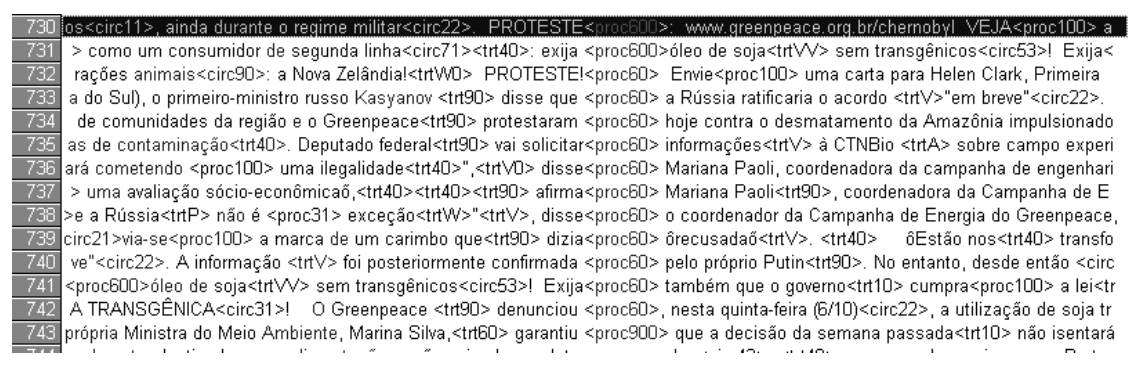

FIGURA 2 - Exemplo de recuperação de etiqueta

Esse levantamento permitiu a comparação sistemática entre as ocorrências dos diferentes processos relacionais. Esse tipo de recurso já foi utilizado por outros estudos em GSF, como é o caso de Shimazumi (1996), que estuda o sistema de transitividade na fala institucional, Wyatt (1997), que trabalha com interação em e-mails e Feitosa (2005), que desenvolveu um sistema aplicável a diversas áreas da GSF.

\section{Resultados}

\section{Os processos relacionais e os participantes das cartas}

Os resultados da análise mostram que os processos relacionais realizam sua função classificatória e caracterizadora nas cartas de mala direta. Contudo, vale ressaltar que essas funções parecem trazer significados diferentes a cada um dos participantes das cartas. Isso ocorre porque cada um deles é representado de forma diferente nesses textos. A TAB. 2, a seguir, mostra que três são as possibilidades de realização dos participantes das cartas pelos papéis de transitividade nos processos relacionais: 1) o produto/serviço; 2) o destinatário e 3) a empresa remetente. 
TABELA 2

Realização dos participantes pelos processos relacionais nas cartas

\begin{tabular}{|c|c|c|c|}
\hline Participantes das cartas & Papéis de transitividade & No & $\%$ \\
\hline \multirow{3}{*}{ Produto/serviço } & Portador & 61 & 61,61 \\
\hline & Identificado & 24 & 24,24 \\
\hline & Possuidor & 14 & 15,15 \\
\hline \multicolumn{2}{|c|}{ Total } & 0 & 100 \\
\hline \multirow{3}{*}{ Destinatário } & Portador & 8 & 18,19 \\
\hline & & & \\
\hline & Possuidor & 36 & 81,81 \\
\hline \multicolumn{2}{|c|}{ Total } & 44 & 100 \\
\hline \multirow{3}{*}{ Empresa remetente } & Portador & 32 & 56,14 \\
\hline & Identificado & 20 & 35,08 \\
\hline & Possuidor & 5 & 8,78 \\
\hline \multicolumn{2}{|c|}{ Total } & 57 & 100 \\
\hline
\end{tabular}

Observa-se que os produtos/serviços anunciados realizam a grande maioria dos participantes dos processos, sendo que a empresa remetente (segundo mais freqüente) e o destinatário, se somados, possuem menos da metade das realizações do produto/serviço. Esses resultados são importantes por mostrarem que os processos relacionais parecem ser utilizados primariamente como forma de caracterização daquilo que é anunciado. A TAB. 2 também traz algumas diferenças entre os participantes. Por exemplo, no caso do produto / serviço, o Portador é o mais freqüentemente instanciado - (ex. 3) -; já o destinatário realiza o Possuidor mais freqüentemente - (ex. 4) -; ao passo que a empresa remetente realiza mais freqüentemente o portador - (ex. 4a), o que contribui para construções de representações específicas dos participantes. No caso dos documentos analisados nesta pesquisa, pôde-se observar que cada um desses participantes tem uma diferente representação nas cartas, sendo que ela parece estar relacionada a determinadas escolhas processuais. Essas escolhas servem a diferentes funções de caracterização

Ex. 3

O ACMEvida [Participante: Portador] é [Processo: relacional atributivo] um seguro[Participante: Atributo]... 
Ex. 4

Você [Participante: Possuidor] conta com [Pr. Relacional Possessivo] até $\mathrm{R} \$ 1.500,00$ [Participante: Possuído] para o pagamento de aulas particulares [Circunstância: Causa (propósito)].

Ex. $4 \mathrm{a}$

$<$ Nós> [Participante: Portador] Somos [Processo: Relacional Atributivo] especializados na área contábil [Participante: Atributo]...

Os processos nos quais os papéis de transitividade são instanciados pelo produto/serviço são apresentados pela tabela a seguir. Os resultados mostram que a descrição do que é anunciado ocorre de três formas: 1) classificação; 2) identificação e 3) constituição.

TABELA 3

Processos dos produtos / serviços

\begin{tabular}{l|l|c}
\hline \multicolumn{2}{c|}{ Tipos de processos } & Freqüência \\
\hline \multirow{3}{*}{ Classificação } & Estar & 23 \\
& Ser & 55 \\
& Tratar-se & 7 \\
\hline \multirow{2}{*}{ Identificação } & Ser & 32 \\
& Tratar-se & 2 \\
\hline \multirow{2}{*}{ Constituição } & Ter & 13 \\
& Possuir & 1 \\
\hline Informação & Ter & 3 \\
\hline
\end{tabular}

Nos processos de classificação, explica-se o que é anunciado pela sua classe/conjunto, formado por uma série de outros produtos/serviços da mesma espécie. Há, assim, a inserção do que é anunciado em uma classe, o que parece ligá-lo a uma representação comum na comunidade em que o destinatário está inserido. Nesses processos, o que é anunciado exerce a função de Portador. Ou seja, ao se classificar um serviço como seguro (ex. 5), o escritor está diferenciando tipos de serviço financeiro; da mesma forma, ao classificar uma publicação como roteiro turístico (ex. 6), ela é diferenciada dos outros tipos que possam existir. 
Ex. 5

O ACMEvida [Participante: Portador] é [Processo: relacional atributivo] um seguro[Participante: Atributo]...

Ex. 6

$<$ o Suplemento > [Participante: Portador] Será [Processo: relacional atributivo] um roteiro turístico que servirá como guia para centenas de famílias... [Participante: Atributo]

A classificação do produto/serviço parece exigir conhecimento do leitor, uma vez que, se ele não compartilhar a representação sugerida pelo escritor, ele pode não ser a pessoa para quem aquela carta é dirigida, uma vez que as categorias de produto representadas pelos atributos não são explicadas nas cartas.

Ex. 7

Trata-se [Processo: relacional atributivo] de um Suplemento Especial [Participante: Atributo] que trará...

Ex. 8

Isso propiciou a utilização de um novo e valorizado espaço comercial [Participante: Atributo], que são [Processo: relacional atributivo] os rodapés exclusivos [Participante: Portador]...

Entre esses processos, trataré um caso interessante para análise. Houve algumas dificuldades na classificação desse processo, uma vez que ele obviamente não é verbal (outra possível classificação). Duas seriam as soluções possíveis para esse impasse. Uma, colocada por Halliday (1994), sugere que a substituição de processos por seus sinônimos (probing) pode ajudar a estabelecer o campo semântico de um dado processo, como vemos nos exemplos a seguir.

Ex. 9

É [trata-se do] o novo crédito automático ACME...

Ex. 10

É [trata-se de] um suplemento especial que... 
Outra solução possível é discutida por Lima-Lopes e Ventura (2006, Mimeo.). Em seu trabalho, os autores sugerem que a colocação dos processos (HALLIDAY; HASAN, 1976; SINCLAIR, 1991) pode ser utilizada como estratégia para categorização. No caso específico de tratar, os autores sugerem que seu significado verbal ${ }^{5}$ não carrega a partícula se, como podemos observar nos exemplos a seguir, retirados do Banco de Dados de Português.

Ex. 11

Baguete - Workshop [Participante; dizente] trata de [Processo: Verbal] segurança na Internet [Participante: Verbiagem].

Ex. 12

Revista Morus [Participante; dizente] trata de [Processo: Verbal] Renascimento e utopia[Participante: Verbiagem].

Ex. 13

<ACME educação > [Participante: identificado] Trata-se do [Processo: relacional identificativo] novo Crediário automático ACME [Participante: Identificador]

$\mathrm{Na}$ identificação, o produto/serviço é colocado em uma posição de destaque em relação aos demais produtos de seu tipo, o que ocorre em proposições nas quais o Identificado é instanciado por aquilo que é anunciado. Por exemplo, o produto/serviço é definido como o melhor disponível, como no ex. 14 , ou como uma novidade no mercado, como noex. 15. Essa particularização é uma forma de persuasão baseada na avaliação ${ }^{6}$ do que é anunciado, buscando-se fazer com que o destinatário também assuma essa representação do produto/serviço.

${ }^{5}$ De acordo com Halliday (1994), os participantes dos processos verbais podem ser definidos como: 1) dizente (entidade que realiza a ação), 2) verbiagem (a mensagem), 3) alvo (entidade que sofre uma ação verbal) e 4) receptor (entidade que recebe a ação). Por exemplo: Ele [Dizente] falou [Processo verbal] mal [Verbiagem] de mim [alvo] para Maria [Receptor].

${ }^{6}$ Thompson e Huston (2000) definem avaliação como (...) the broad cover term for the expression of the speaker or writer's attitude or stance toward, viewpoint on, or feelings about the entities or propositions that he or she is talking about". (THOMPSON; HUSTON, 2000, p. 5) 
Ex. 14

Sua melhor opção [Participante: Identificador] é [Processo: relacional identificativo] o ACME, seu consultor econômico [Participante: identificado].

Ex. 15

O novo processador ACME III de $466 \mathrm{MHz}$ [Participante: identificado] é [Processo: relacional identificativo] a mais recente aquisição [Participante: identificador]...

Isso mostra que os processos relacionais intensivos e identificativos possuem funções diferentes na caracterização do produto/serviço anunciado. Ramos (1997) - que estuda a projeção de papéis em material promocional propõe que a escolha do Portador pode ser baseada na definição do públicoalvo dos documentos:

... se esse público é o consumidor, a qualidade do produto/serviço é o item particularizado. Se o público é o investidor, o importante é o calibre do gerenciamento. (RAMOS, 1997, p. 199)

ao passo que a escolha do identificador é baseada na necessidade de definição da empresa:

Nesse caso, a empresa se identifica dizendo ao leitor que ela éX e não $Y$. (RAMOS, 1997, p. 199).

As colocações de Ramos são importantes por mostrarem que a escolha dos participantes está condicionada pelos objetivos do texto. Assim, ao classificar o produto/serviço, o escritor não só está definindo o que é anunciado, como também está selecionando o seu leitor, que, para entender essa definição, deve possuir conhecimentos específicos. Já nos processos de identificação, o produto/serviço é definido como o melhor, identificando-se com valores positivos que os destacam dos demais.

Quanto aos processos de constituição, há a explicação das partes ou facilidades oferecidas pelo produto/serviço. Os exemplos a seguir mostram que, ao se explicar um software para contabilidade - que é o Possuidor -, são destacadas algumas de suas funções, vantagens ou elementos constituintes que são os Possuídos. 
Ex. 16

Os sistemas [Participante: Possuidor] possuem [Processo: relacional possessivo] teclas de funções... [Participante: Possuído].

Ex. 17

É o único [Participante: Possuidor] <cartão> que tem [Processo: relacional possessivo] juros decrescentes [Participante: Possuído]...

Em alguns casos, esses processos de constituição parecem também servir como uma forma de caracterização daquilo que é anunciado, o que parece thes dar uma função muito próxima das realizadas pelos processos intensivos, não indicando apenas a noção de posse ou de constituição. Um exemplo seria o ex. 18 , no qual a tiragem, que normalmente seria um elemento constituinte da revista, parece também caracterizar seu poder de circulação. Outro caso seria ex.19, exemplo em que a cobertura do veículo serve ao mesmo propósito de caracterização.

Ex. 18

O ACME (Verifique no jornal anexo) [Participante; Possuidor], como é chamado pelos sambernardenses, tem [Processo: relacional possessivo] uma tiragem de 30.000 exemplares [Participante: Possuído]...

Ex. 19

A ACME [Participante: Possuidor], tem [Processo: relacional possessivo] a maior cobertura internacional do Cone-Sul [Participante: Possuído]...

Este estudo corrobora os resultados de Ramos (1997, p. 200), que chama a atenção para o fato de algumas das realizações dos Possuídos serem, na verdade, Metas $^{7}$ que têm a função de caracterizar a empresa (que, no seu estudo, realizam os Possuidores). Essa semelhança pode ser resultado do tipo de função: tanto os processos materiais como os relacionais trazem

\footnotetext{
7 De acordo com Halliday e Matthiessen (2004), os participantes dos processos Materiais são: Ator (que realiza a ação), Meta (que é modificado pela ação), Receptor (a quem uma ação é direcionada ou enviada), Cliente (entidade por quem algo é feito), Escopo (responsável pela complementação do significado do processo. Ex.: Ele [Ator] deu [Processo material] uma casa [Meta] para a filha [Receptor].
} 
informações sobre o desempenho do produto/serviço. Uma das implicações desses resultados é a equivalência no uso desses processos.

Ex. 20

$<$ O jornal ACME $>$ [Participante: Possuidor/Ator] tem uma tiragem de/vende [Processos] 30.000 exemplares [Circunstância/Meta].

Os processos de informação são os que ocorrem em menor número entre o produto/serviço anunciado. Apesar de estarem em uma estrutura possessiva, esses processos parecem trazer um significado relacionado à descrição do produto/serviço anunciado, como mostram os exemplos a seguir.

Ex. 21

Com sua linha editorial [Participante: Possuidor], que tem [Processo: relacional possessivo circunstancial] como principal característica a denúncia de problemas [Participante: Circunstância] ... .

Ex. 22

O ACME é um jornal com 62 anos de experiência [Participante: Possuidor], e tem [Processo: relacional possessivo] o seu editorial voltado ao segmento econômico-financeiro do País [Participante: Possuído].

Como mostra a TAB. 4, os processos em que o destinatário realiza papéis de transitividade podem ser divididos em duas categorias: a) processos de aproximação e b) processos de descrição.

Tabela 4

Processos do destinatário

\begin{tabular}{|c|c|c|c|}
\hline Categoria & Processo & No & $\%$ \\
\hline Aproximação & $\begin{array}{c}\text { Encontrar } \\
\text { Ser } \\
\text { Ficar } \\
\text { Ter } \\
\end{array}$ & $\begin{array}{c}3 \\
6 \\
4 \\
12 \\
\end{array}$ & $\begin{array}{l}12 \\
24 \\
16 \\
48 \\
\end{array}$ \\
\hline \multicolumn{2}{|c|}{ Total } & 0 & 100 \\
\hline Descrição & $\begin{array}{c}\text { Contar } \\
\text { ter }\end{array}$ & $\begin{array}{l}6 \\
7 \\
\end{array}$ & $\begin{array}{l}46,15 \\
53,84\end{array}$ \\
\hline \multicolumn{2}{|c|}{ Total } & 13 & 100 \\
\hline
\end{tabular}


Os processos de aproximação ocorrem em proposiçóes que têm o objetivo de estabelecer uma relação de proximidade com o destinatário. Procura-se mostrar como o destinatário é importante para a empresa remetente e para o produto que ela comercializa, como mostram os exemplos (ex. 23) e (ex. 24). A relação entre o destinatário e a empresa é marcada pelo elemento circunstancial em itálico, em (ex. 23). Em (ex. 24), observa-se que o serviço ocorre em uma circunstância de meio, sendo ele instrumento dessas modificações no dia-a-dia do destinatário das cartas.

Ex. 23

Porque você [Participante: Portador] é [Processo: Relacional Atributivo] muito importante [Participante: Atributo] para nós [Circunstância: Ângulo (Ponto de vista)] e não queremos que deixe de ler nossa revista.

Ex. 24

Você [Participante: Portador] fica [Processo: Relacional Atributivo] mais tranqüilo [Participante: Atributo], sua família mais protegida com as garantias que o seguro ACME oferece [Circunstância: Modo (meio)]...

Assim, tenta-se trazer o destinatário para perto da empresa, ou ainda mostrar como o produto/serviço tem poder de modificar a vida do destinatário. Em ambos os casos, cabe ao destinatário aceitar a relação proposta, sendo que, caso isso ocorra, pode-se dizer que a estratégia empregada na utilização dos elementos de transitividade foi bem-sucedida.

Há um pequeno número de Portadores instanciados por entidades em $3^{\text {a }}$ pessoa, como em:

Ex. 25

Para nós [Circunstância: Ângulo (Ponto de vista)], os leitores de ACME [Participante: Portador] são [Processo: relacional atributivo] muito valiosos [Processo: Atributo].

Ex. 26

Com o empréstimo ACME [Circunstância: Meio], as férias da família [Participante: Portador] ficam [Processo: Relacional Atributivo] muito melhores [Participante: Portador]. 
Essas entidades são clientes para os quais um determinado produto ou serviço é direcionado. Uma vez que o destinatário e o cliente realizam a mesma função dentro da proposição, o remetente está igualando-os no nível textual, talvez para levar o destinatário a assumir essa representação no mundo extratextual. Essa estratégia é baseada em um jogo de representações: tanto o cliente como o destinatário são representados da mesma forma, sendo que caso o destinatário se inclua nessa categoria, ele estará se colocando entre aqueles dos quais a empresa está querendo se aproximar.

Os processos de descrição ocorrem apenas nas cartas que vendem serviços financeiros, sendo que o destinatário é Possuidor de indenizações ou serviços oferecidos por companhias de seguro, como no ex. 28, ou de serviços diversos, oferecidos por instituições financeiras, como no ex. 29. Esses processos trazem informações sobre o que o destinatário terá ao adquirir o serviço anunciado, representando o destinatário como usuário do serviço (podendo gozar, portanto, daquilo que ele oferece).

Ex. 27

Você [Participante: Possuidor] conta com [Processo: Relacional Possessivo] até $\mathrm{R} \$ 1.500,00$ [Participante: Possuído] para o pagamento de aulas particulares [Circunstância: Causa (propósito)].

Ex. 28

Você [Participante: Possuidor] conta com [Processo: Relacional Possessivo] o valor acima que já está pré-aprovado [Participante: Possuído]...

Alguns desses processos relacionais merecem alguma observação mais detalhada de sua classificação. Um deles seria encontrar, que teria duas classificaçóes possíveis: uma relacional e outra material, sinônimo de achar (LIMA-LOPES; VENTURA 2006). No caso de ex. 29 e ex. 30, retirados do corpus de análise desta pesquisa, podemos observar que os significados Relacionais são de caráter circunstancial, indicando localização. Além disso, pode-se observar que esse processo ocorre em sua forma reflexiva.

Ex. 29

Seu nome já [Participante: Portador] se encontra [Processo: Relacional Atributivo Circunstancial] na portaria [Circunstância: Localização (lugar)] na lista de convidados [Circunstância: Localização (lugar)]. 
Ex. 30

Na mesma região onde [Circunstância: Localização (lugar)] você [Participante: Portador] já se encontra [Processo: Relacional Atributivo Circunstancial].

O mesmo acontece com os exemplos retirados do Banco de Dados de Português, os quais possuem uma instanciação e uma estrutura gramatical bastante semelhantes:

Ex. 31

Meu currículo [Participante: Portador] encontra-se [Processo: Relacional Atributivo Circunstancial] em anexo para sua apreciação [Circunstância: Localização (lugar)].

Ex. 32

Se você [Participante: Portador] se encontra [Processo: Relacional Atributivo Circunstancial] nesta situação [Circunstância: Localização (lugar)] ...

Já em seu significado material, encontrar parece não ocorrer em sua forma reflexiva, podendo não realizar significados circunstanciais, como mostram os exemplos a seguir, retirados do Banco de dados de Português:

Ex. 33

Quando [Circunstância: Localização (tempo)] você [Participante: Ator] encontra [Processo: Material] dificuldades [Participante: Meta] na sua sala de aula [Circunstância: Localização (lugar)].

Ex. 34

... ele [Participante: Ator] encontra [Processo: Material] a sua espada [Participante: Meta]...

Esse tipo de fraseado também está presente nas instâncias de encontrar que realizam significados materiais no corpus de estudo desta pesquisa:

Ex. 35

... nas páginas de ACMEDinheiro [Circunstância: Localização (lugar)] você [Participante: Ator] encontra [Processo: Material]: Dinheiro na Semana [Participante: Meta]... 
O verbo contar também possui mais de uma classificação possível (LIMA-LOPES; VENTURA, 2006). Dependendo do contexto de ocorrência, esse processo poderia ser classificado como verbal, no sentido de verificar a quantidade ou relatar fatos. Nenhuma dessas classificações parece se adequar ao caso das ocorrências desse processo nas cartas, como mostra o exemplo abaixo:

Ex. 36

E o melhor: [Circunstância: modo (qualidade)] durante 24 horas por dia [Circunstância: localização (lugar)], você [Participante: possuidor] conta [tem] com [Processo:; Relacional] este benefício [Participante: Possuído]. . .

De fato, pode-se observar que, novamente, a diferença entre esses significados manifesta-se, também, em diferenças nos padrões de colocação e coligação de contar, pois o significado Relacional vem constantemente acompanhado da preposição com, o que não ocorre em seus significados verbais. Podemos observar essa relação nos exemplos a seguir, retirados do corpus de comparação.

Ex. 37

Mantenha o pregador aberto enquanto <você $>$ [Participante: Dizente] conta [Processo: verbal] até vinte [Circunstância: Assunto]

Ex. 38

Livro [Participante: Dizente] conta [Processo: verbal] dez anos de Audi [Circunstância: Lugar] no BR História da marca alemã...

Outro significado importante trazido pelos processos de descrição é a colocação de descontos e vantagens, condicionados pela aquisição do produto/ serviço anunciado. Nesse caso, temos o destinatário como possuidor dessas vantagens: ex 39, ex 40 e ex 41.

Ex. 39

Você [Participante: Portador] conta [Processo: Relacional] com 30 dias de transporte gratuito[Participante: Possuído]. . .

Ex. 40

Abrindo sua conta até (...) [Circunstância: Localização (Tempo)] você [Participante: Portador] terá [Processo: Relacional] direito ao exclusivo pacote ACME de vantagens [Participante: Possuído]. 
Ex. 41

Na primeira fita "Vulcão" [Circunstância: Localização (lugar)] você [Participante: Portador] tem [Processo: Relacional] direito a 20\% de desconto [Participante: Possuído]...

TABELA 5

Processos relacionados à empresa remetente

\begin{tabular}{l|l|l|c}
\hline \multicolumn{2}{l|}{ Categoria } & Processo & Freqüência \\
\hline Descrição & Identificação & Ser & 1 \\
& Classificação & Ser & 5 \\
\hline Total & & 6 \\
\hline Aproximação & Ser & 6 \\
& Estar & 1 \\
\hline & Ficar & 5 \\
\hline Total & & 12 \\
\hline
\end{tabular}

A TAB. 5, acima, traz os processos relacionados à empresa remetente. Com relação a esses processos, os de descrição podem ser de dois tipos 1) identificação e 2) classificação. Nos processos de identificação, a empresa é associada a valores (prosódia semântica positiva) que a destacam em relação às outras empresas de sua área, retratando o seu grau de excelência, como mostra o ex. 42, sendo que essa relação de identificação pode ocorrer também por meio de um elemento circunstancial (ex. 43), que não foi encontrado no Banco de Dados de Português. Isso talvez possa significar que esse tipo de realização seja algo não tão comum em português, exigindo estudos mais aprofundados. Outro ponto a ser observado é a utilização de uma oração projetada realizando o papel de Identificado em ex. 42. Ocorrências desse fenômeno foram encontradas no Banco de Dados de Português, como podemos ver no ex. 44 e no ex. 45 .

Ex. 42

<Essa promoção> [Participante: Identificador] É [Processo: Relacional identificativo] a ACME pensando na satisfação de seus clientes [Participante: Identificado]... 
Ex. 43

A ACME informática [Participante: Dizente] se propõe [Processo: Verbal] em primeiro lugar [Circunstância: Localização (lugar)] em ser a melhor sem ser a maior [Circunstância: Modo]

Ex. 44

... é [Processo: Relacional identificativo] o sentido [Participante: Identificado]... o QUE é que vai caracterizar a oração [Participante: Identificador]?

Ex. 45

O grande problema [Participante: Identificador] é [Processo: Relacional identificativo] que grupos armados fora do Estado tendem a [Participante: Identificado]...

Já os processos de classificação possuem uma função muito semelhante a já realizada nos produtos/serviços. Aqui, a empresa remetente é caracterizada positivamente, como vemos nos exemplos a seguir. Apesar dessa pesquisa não ter seu foco nas escolhas do sistema de Modo, vale a pena ressaltar a constante utilização do pronome inclusivo "nós" como elemento que nomeia a empresa remetente (ex. 47). Esse tipo de escolha parece ser comum em documentos comerciais, como é o caso dos relatórios anuais e suas traduções para o inglês (SIQUEIRA, 2000) e de diversos documentos comerciais em inglês (THOMPSON; RAMOS, 1995; RAMOS, 1997). Essa consonância de resultados mostra que algumas escolhas no nível do discurso podem ser a mesma em diferentes gêneros da linguagem dos negócios. Logicamente, pesquisas específicas que comprovem essa hipótese são necessárias.

Ex. 46

A Empresa ACME Máquinas e equipamentos LTDA. [Participante: Portador] é [Processo: Relacional Atributivo] uma sólida e conceituada empresa atuando... [Participante: Atributo]

Ex. 47

$<$ Nós> [Participante: Portador] Somos [Processo: Relacional Atributivo] especializados na área contábil [Participante: Atributo]... 
Ex. 48

A ACME Consultoria de Comunicação e Marketing[Participante: Portador] e' [Processo: Relacional Atributivo] uma empresa especializada na edição e montagem de revistas e jornais dirigidos... [Participante: Atributo]

Por fim, as estratégias de aproximação objetivam criar uma relação solidária entre a empresa remetente e o destinatário, tentando mostrar como a empresa está próxima do leitor das cartas. Aqui, o portador passa a ser a empresa, ao passo que o destinatário ocorre em um elemento circunstancial:

Ex. 49

ACME, a Empresa [Participante: Portador] que está [Processo: Relacional Circunstancial Atributivo] mais perto de você [Circunstância: Localização (espaço) $\ldots$

A função desses processos pode ser também levar o destinatário a realizar um contato direto com a empresa remetente:

Ex. 50

$<$ Nós> [Participante: Portador] Estamos [Processo: Relacional Circunstancial Atributivo] a sua inteira disposição [Circunstância: Causa (Benefício)] para quaisquer esclarecimentos [Circunstância: Causa (Propósito)]...

Ex. 51

...nossa equipe [Participante: Portador] está [Processo: Relacional Circunstancial Atributivo] à sua disposição [Circunstância: Causa (Benefício)] para maiores informaçôes [Circunstância: Causa (Propósito)]...

Ex. 52

$\ldots<$ Nós $>$ [Participante: Portador] ficamos [Processo: Relacional Circunstancial Atributivo] ao seu inteiro dispor [Circunstância: Causa (Benefício)] para qualquer esclarecimento que se teça [Circunstância: Causa (Propósito)].

É importante observar que esses significados são realizados por uma forma bastante estável: o destinatário ocorre em uma circunstância de benefício: à/ao (seu/sua) dispor/disposição, ao passo que a empresa remetente é sempre o Portador. Um dos efeitos dessa escolha é mostrar que a empresa remetente é responsável por uma ação de benefício que recai sobre destinatário, que não 
realiza uma ação concreta nesse significado e realiza apenas o "pano de fundo" sob o qual a ação se realiza. Pode-se afirmar que esse resultado está em consonância com outros estudos relacionados aos processos relacionais nesse gênero. Em Lima-Lopes (2005b, 2001), pude observar que o principal papel desempenhado pelo destinatário nesses documentos é o de Beneficiário, tendo a empresa ou o produto anunciado como Ator e, portanto, benfeitor. Isso mostra que o destinatário tende a realizar papéis mais passivos em instanciações em que a empresa remetente também está presente.

\section{Algumas considerações}

Os resultados da análise desenvolvida neste trabalho mostram que os processos relacionais realizam várias funçōes dentro das cartas, funções que parecem ser motivadas pelo propósito comunicativo desse gênero. $O$ primeiro ponto a ser observado é a maior freqüência do produto/serviço nas instanciações de processos relacionais, estando presente não só Possuidor/ Portador/Identificado, mas também como Possuído em algumas instanciações em que o Destinatário desempenha o papel de Possuidor. Isso mostra que a sua caracterização é o elemento central não só na realização desses processos, como dessas cartas (LIMA-LOPES, 2001, 2005b). Em segundo lugar, constata-se que a importância da empresa remetente nas cartas está no fato de ser a responsável pelas informações ali colocadas, ou seja, é ela que assegura a qualidade daquilo que é anunciado durante sua descrição. Já o destinatário parece ter um lugar secundário no sistema de instanciação relacional, o que se conclui não apenas pela sua baixa freqüência nesses processos, como também pelo menor número de funções a ele atribuídas. Um resumo dessas funções pode ser observado na FIG. 2.

Um ponto a ser observado na análise dos processos relacionais é que as escolhas parecem servir a uma estratégia de caracterização, que parece ser a mesma aplicada tanto ao produto/serviço, como à empresa. Um exemplo disso é a inclusão do produto/serviço e da empresa remetente em uma classe. Ali o escritor parece estar preocupado em definir a empresa - e o produto/serviço - a partir do conhecimento de mundo que ele espera que seu destinatário (e possível comprador) possua, atribuindo-lhes uma representação semelhante: parte de um grupo de produtos e de empresas. Isso também ocorre nos processos de identificação - lugar em que o escritor usa uma estratégia semelhante para avaliar o produto e a empresa - e nas estratégias de aproximação, nas quais a empresa mostra-se próxima do destinatário. 
Segundo Thompson e Thetela (1995), a empresa e o produto/serviço anunciado representam uma mesma entidade, o escritor-no-texto, cuja principal característica é ser benéfica para o destinatário. Os resultados dessa pesquisa corroboram o estudo de Thompson e Thetela, uma vez que o produto/serviço são caracterizados através de um sistema de escolhas semelhante.

Nos processos nos quais o produto/serviço é o possuidor, o que é anunciado é definido a partir de suas partes constitutivas, sendo que esse tipo de descrição parece trazer alguns dados sobre as possibilidades de desempenho. Nos processos em que o destinatário é o Possuidor, essa personagem é retratada como se já tivesse adquirido o serviço, sendo, portanto, seu usuário. Por fim, a empresa remetente funciona como disponibilizadora do produto/serviço oferecido, que é representado como entidade disponibilizada. Ramos (1997) também discute o tipo de entidade a quem as personagens estão ligadas nos processos relacionais. De acordo com a autora, nos processos intensivos, o Identificador e a Característica são instanciados por entidades abstratas, como em:

Company is management (retirado de RAMOS, 1997, p. 200)

ao passo que nos processos relacionais possessivos são sempre instanciados por elementos concretos:

Company has products (retirado de RAMOS, 1997, p. 200)

Esta pesquisa confirma os resultados observados por Ramos. Nos relacionais identificativos e atributivos, o produto/serviço e a empresa remetente são relacionados a valores e categorias abstratas, como em:

Ex. 53

A sua melhor opção é o jornal ACME...

Por outro lado, nos relacionais possessivos, o destinatário, a empresa ou o produto são relacionados a outra entidade concreta:

Ex. 54

... as publicações profissionais, como a ACME, têm uma expressiva carteira de assinantes...

Ex. 55

você tem até $\mathrm{R} \$ 300,00$ em caso de acidente... 
Isso mostra que a classificação das personagens é baseada em idéias ou conceitos subjetivos, que podem variar de acordo com as pessoas envolvidas na interação, ao passo que a descrição do produto/serviço é mais objetiva, sendo baseada nos elementos que o constituem.

Thompson (1998) estuda a motivação para repetição de determinadas estruturas de transitividade em um texto. Para o autor, as escolhas parecem sustentar umas às outras, ajudando a consolidar um determinado tom $(\text { tone })^{8}$, que percorre todo o texto. Para Thompson (1998), o autor de um texto, inconscientemente, cria uma imagem - por exemplo, cidade em movimento ou resultados lógicos - e opta consistentemente por fraseados que mantenham o tom dessa imagem. Thompson (1998) afirma que essa repetição pode ocorrer em níveis mais sutis. Um exemplo são as metáforas gramaticais em brochuras de turismo (a building stands, a street runs) (THOMPSON, 1998, p. 31). No caso específico dos textos de turismo, Thompson explica que essas escolhas, de caráter metafórico, têm por função dar um tom dinâmico ao texto, tom que se perderia caso esses processos não fossem utilizados. $\mathrm{O}$ autor chama esse fenômeno de Ressonância Textual, um efeito cumulativo nas escolhas no sistema de transitividade em um texto, consolidando determinadas facetas do significado. Assim, o produtor de um texto tem possibilidades de realização à sua disposição, mas usa apenas aquelas que mantêm um padrão escolhido (THOMPSON, 1998, p. 32). Embora importante para a unidade do texto, a ressonância não é colocada como um sistema, mas, sim, como uma estratégia no nível do discurso. Um fraseado se torna a escolha mais provável em um contexto porque ele ressoa (resonates) com as demais escolhas, construindo, juntas,o significado trazido pelo texto.

\footnotetext{
${ }^{8}$ A palavra tone não está sendo utilizada em seu sentido mais comum na GSF. Aqui o autor a utiliza no sentido de "algo que percorre todo o texto", como se pode observar em: The aspect that we are concerned with might informally be called the "tone" of a text: the overall cumulative effect of the way in which certain transitivity choices seem to reinforce each other. . (THOMPSON, 1998, p. 30).
} 


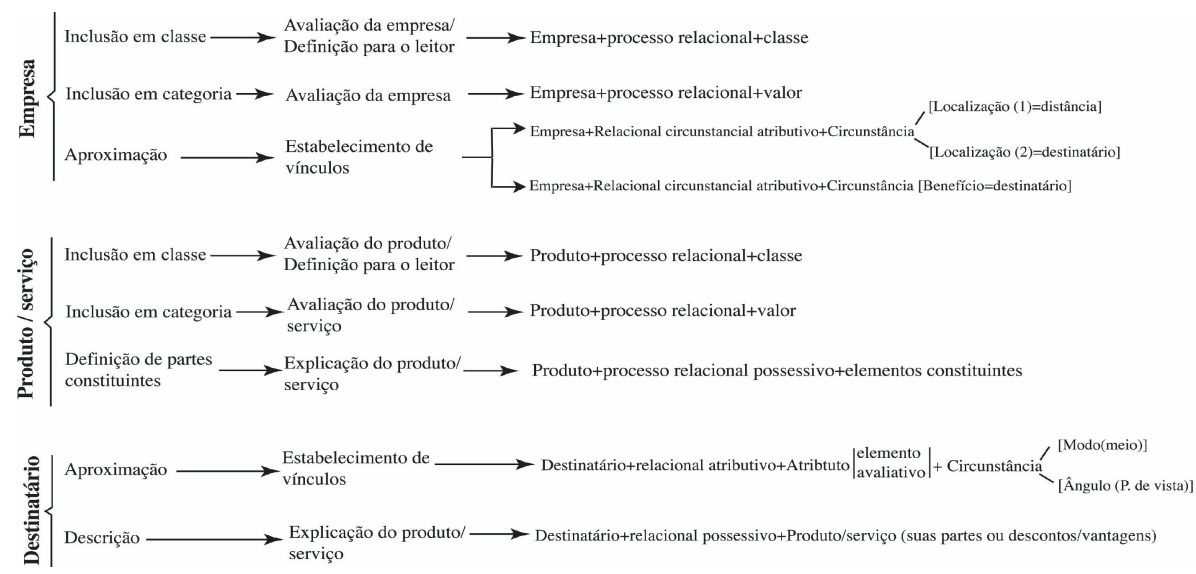

FIGURA 3 - Resumo das funçōes realizadas pelos processos relacionais

Na FIG. 3, podemos observar a existência de uma relativa semelhança entre as funções realizadas pelos participantes. Apesar das diferentes escolhas, pode-se verificar que o número de funções realizadas não ultrapassa quatro, realizando uma forma de ressonância. De fato, observa-se que essa representação de funções parece contribuir para a manutenção de representações dos participantes. Essas representações se repetem ao longo dos documentos e mantêm presente uma idéia central.

Dessa forma, essa consistência de representações e funções parece servir como uma expressão da unidade textual. No caso das funções, elas seriam responsáveis por determinar qual o papel de cada participante da interação, além de ajudar a determinar seu escopo. Ao mesmo tempo, essas funçôes e representações estão presentes em todos os documentos estudados, o que pode levar à conclusão de que esse fenômeno trabalha em dois níveis: um local e, portanto, responsável pela manutenção dessa representação ao longo do texto, e outro mais geral, responsável pela identidade do próprio gênero. Isso é de fato observado em outros estudos, que comparam os vários processos nesse mesmo corpus de estudo. Em Lima-Lopes (2001), pude observar que esse efeito de ressonância também ocorre entre os processos. Uma possível explicação para esse fato pode ser a necessidade de criar uma representação que seja independente do tipo de processo instanciado, mostrando que a relação entre o destinatário, a empresa e o produto/serviço é constante. Por exemplo, o destinatário será sempre representado como usuário do produto/serviço, o que pode acontecer ora pelo uso - realizando os Atores - ora pela posse - realizando os Possuidores. Já a empresa será sempre disponibilizadora e criadora (Ator ou Possuidor) do produto/serviço (Meta/extensão ou Possuído). 
Por fim, vale observar também que este trabalho traz contribuições importantes para a análise de transitividade em língua portuguesa, uma vez que a existência de poucos estudos em nosso idioma cria lacunas que ainda precisam ser preenchidas. Todavia, é importante ter em mente que os estudos sobre esse tema precisam ir além da simples classificação de processos, observando qual sua implicação no nível do discurso. Outro fator importante é a questão metodológica: vários estudos baseados em GSF estão utilizando a LC (SHIMAZUMI, 1996; WYATT, 1997; FEITOSA, 2005; RODRIGUES JUNIOR, 2006) como instrumento metodológico. De fato, esse casamento é bastante profícuo, não apenas pelo fato de as duas abordagens possuírem uma origem comum (STUBBS, 1996), mas também porque sua utilização possibilita uma série de contribuições para o analista. Entre elas estariam: estudo de maiores quantidades de texto, possibilidade de levantamento exaustivo, maior velocidade de análise, maior possibilidade de replicabilidade e maior confrabilidade estatística (KENNEDY, 1998, p. 5).

\section{Referências}

ARMBRUST, C. As funçôes das construçôes passivas em editoriais em português e em inglês: um estudo a luz da perspectiva sistêmico-funcional. 2006. Dissertação (Mestrado em Lingüística Aplicada e Estudos da Linguagem) - LAEL - PUCSP, São Paulo, 2006.

BIBER, D.; CONRAD, S., et al. Corpus Linguistics: investigating language strutucture and use. Cambridge: Cambridge University Press, 1999.

BERBER SARDINHA, A. P. Lingüística de corpus: histórico e problemática. DELTA, v. 16, n. 2, p. 326-367, 2000.

BRESSANE, T. B. R. Construção de identidade numa empresa em transformação. 2000. Dissertação (Mestrado em Lingüística Aplicada e Estudos da Linguagem) - LAEL - PUCSP, São Paulo, 2000.

CESCA, C. G. G. Comunicação dirigida escrita na empresa. São Paulo: Summus Editorial, 1995.

EGGINS, S. An introduction to systemic functional grammar. London: Printer Publishers, 1994.

FEITOSA, M. P. Uma Proposta de anotação de corpora paralelos com base na Lingüistica Sistêmico-Funcional. 2005. Dissertação (Mestrado em Estudos Lingüísticos) - FALE/UFMG, 2005.

HALLIDAY, M. A. K. Explorations in the Functions of Language. London: Edward Arnold, 1973. 
HALLIDAY, M. A. K. Language as social semiotic. London: Edward Arnold, 1978. 1985. An introduction to Functional Grammar.1. ed. London: Edward Arnold,

. Corpus studies and probabilistic grammar. In: AIJMER, K.; ALTERNBERG, B. (Ed.). English corpus linguistics. London: Longman, 1991. . Language as system and language as instance: the corpus as a theoretical construct. In: SVARTIVIK, J. (Ed.). Directions on Corpus Linguistics. Proceedings of the Nobel Symposium 82. Berlin: Mouton de Gruyer, 1992a.

. Some lexicogrammatical features of the Zero Population Growth Text. In: MANN, W. C.; THOMPSON, S. A. (Ed.). Discourse Description: Diverse linguistic analyses of a fund-raising tex. Amsterdan: John Benjamim, 1992b.

Quantitative studies and probabilities in grammar. In: HOEY, M. (Ed.). Data, description, discourse. New York: Harper Collins, 1993.

. An Introduction to Functional Grammar. 2. ed. London: Edward Arnold, 1994.

HALLIDAY, M. A. K.; MATTHIESSEN, C. M. I. M. Construing Experience through meaning: A language approach to cognition. London / New York: Continnuum, 1999.

. An Introduction to Functional Grammar. 3. ed. London: Edward Arnold, 2004.

HALLIDAY, M. A. K.; HASAN, R. Cohesion in English. London: Longman, 1976.

HEBERLE, V. M. A representação das experiências femininas em editoriais de revistas para mulheres. Discurso y Sociedad, v. 1, n. 3, 1999.

KENNEDY, G. An introduction to corpus linguistics. London: Longman. 1998.

LEECH, D. The state of the art in corpus linguistics. In: AIJMER, K.; ALTENBERG, B. (Ed.). English corpus linguistics. London: Longman, 1991.

LIMA-LOPES, R. E. D. Estudos de Transitividade em Lingua Portuguesa: O Perfil do Gênero Cartas de Venda. 2001. Dissertação (Mestrado em Lingüística Aplicada e Estudos da Linguagem) - Faculdade de Letras, Pontifícia Universidade Católica de São Paulo, 2001.

Avaliação de um sistema de marcação textual Aplicado à Gramática Sistêmico-Funcional. In: BERBER SARDINHA, A. P. (Ed.). A Lingua Portuguesa no Computador. Campinas: Mercado de Letras, 2005a.

Levantamento de processos materiais em cartas de venda. Trabalhos em Lingüistica Aplicada, v. 44, n. 1, p. 133-160, 2005 b. 
LIMA-LOPES, R. E. D.; VENTURA, C. S. M. A transitividade em Português. São Paulo, 2006. (Manuscrito não publicado)

MANSON, O. Qwick - Software for lexical analysis, 1999.

MARTIN, J. R.; MATTHIESSEN, C. M. I. M.; PAINTER, C. Working with functional grammar. London: Edward Arnold, 1997.

MATTHIESSEN, C. M. I. M. The System of Transitivity: an exploratory texbased profile. Functions of Language, v. 6, n. 1, p. 1-51, 1999.

MCENERY, T.; WILSON, A. Corpus Linguistics. Edinburgh: Edinburgh University Press, 1996.

NUS, M. V. Can we count on your booking of potatoes to Madeira- Corporare context and discourse practices in direct sales letters. In: BARGIELACHIAPPINI, F.; NICKERSON, C. (Ed.). Writing business: genres, media and discourses. London and New York: Longman, 1999.

PINHO, J. B. Propaganda Institucional: usos e funções da propaganda em relações públicas. São Paulo: Sumus Editorial, 1990.

RAMOS, R. C. G. Projeção de imagens através de escolhas lingüisticas: um estudo no contexto empresarial. 1997. Tese (Doutorado em Lingüística Aplicada e Estudos da Linguagem) - Faculdade de Letras, Pontifícia Universidade Católica de São Paulo, 1997.

RODRIGUES JUNIOR, A. S. A representação de personagens gays na coletânea de contos Stud e em sua tradução As Aventuras de um Garoto de Programa. 2006. Tese (Doutorado em Lingüística Aplicada). Faculdade de Letras, Universidade Federal de Minas Gerais, Belo Horiznte, 2006.

SCOTT, M. R. WordSmith Tools - Software for lexical analisys. Oxford: OUP, 1999.

SHIMAZUMI, M. The knower and the Informant in Institutional talk: A transitivity Perspective. (MA in Linguistics). University of Liverpool, 1996.

SINCLAIR, J. Corpus, Concordance, Colocation. Oxford: OUP, 1991

SINCLAIR, J.; MANSON, O. et al. Language independent statistical software for corpus exploration. Computers and the Humanities, v. 31, 1998.

SIQUEIRA, C. P. Análise temática em estudos de tradução - O caso do relatórios anuais de empresas brasileiras. 2000. Dissertação (Mestrado em Lingüística Aplicada e Estudos da Linguagem). - Faculdade de Letras, Pontifícia Universidade Católica de São Paulo, 2000.

STUBBS, M. Text and corpus analysis. London: Blackwell, 1996.

THOMPSON, G. Introducing functional grammar. 2. ed. London: Edward Arnold, 1996. 
THOMPSON, G. Resonance in text. In: SÁNCHEZ-MACARRO, A.; CARTER, R. (Ed.). Linguistic choice across genres: variation in spoken and written English. Amsterdam: John Benjamins, 1998.

THOMPSON, G.; HUNSTON, S. Evaluation: An introduction. In: THOMPSON, G.; HUNSTON, S. (Ed.). v.Evaluation in text - authorial stance and the construction of discourse. Oxford: Oxford University Press, 2000.

THOMPSON, G.; RAMOS, R. C. G. Ergativity in the analysis of business texts. Direct Papers - CEPRIL, PUCSP, AELSU, Liverpool University, v. 21, 1995.

THOMPSON, G.; THETELA, P. The sound of one hand clapping: the management of interaction in written discourse. Text, v. 15, n.1, p. 103-127, 1995.

WYATT, R. D. The complete consort dancing together... interaction in E-mail. 1997. Dissertação (Mestrado em Lingüística Aplicada e Estudos da Linguagem)

- Faculdade de Letras, Universidade Católica de São Paulo, 1997. 


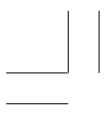

